05

\title{
Термочувствительный спиновый клапан на основе искусственного ферримагнетика: процесс намагничивания в широком диапазоне полей
}

\author{
(C) А.В. Свалов ${ }^{1}$, Е.А. Степанова ${ }^{1}$, В.О. Васьковский ${ }^{1,2}$, Г.В. Курляндская ${ }^{1,3}$ \\ ${ }^{1}$ Институт естественных наук и математики, Уральский фредеральный университет им. Б.Н. Ельцина, \\ Екатеринбург, Россия \\ ${ }^{2}$ Институт фризики металлов им. М.Н. Михеева РАН, \\ Екатеринбург, Россия \\ ${ }^{3}$ Университет Страны Басков, Бильбао, Испания \\ E-mail: andrey.svalov@urfu.ru
}

Поступила в Редакцию 15 апреля 2019 г.

В окончательной редакции 22 апреля 2019 г.

Принята к публикации 24 апреля 2019 г.

\begin{abstract}
Разработаны, получены и исследованы пленочные структуры типа $\mathrm{Gd}-\mathrm{Co} / \mathrm{Co} / \mathrm{Cu} / \mathrm{Co}$, обладающие свойствами термочувствительных спиновых клапанов. Для них представлены результаты магнитных и магниторезистивных измерений в широком диапазоне полей и температур. Показано, что возникновение неколлинеарной магнитной структуры в системе Gd-Co/Co существенным образом влияет на форму магниторезистивной петли гистерезиса. Величина критических полей перемагничивания зависит от температуры и может варьироваться за счет изменения соотношения толщин слоев пленочной системы.
\end{abstract}

Ключевые слова: спиновый клапан, ферримагнетизм, магнитосопротивление.

DOI: $10.21883 /$ FTT.2019.09.48107.13N

\section{1. Введение}

Концепция термочувствительного спинового клапана, а также возможность ее реализации были предложены и продемонстрированы сравнительно недавно [1-3]. В качестве такого клапана в работе [1] была использована многослойная структура типа $\mathrm{Gd}-\mathrm{Co} / \mathrm{Co} / \mathrm{Cu} / \mathrm{Co}$, в которой термочувствительность обеспечивается выраженной температурной зависимостью коэрцитивной силы двухслойной пленки $\mathrm{Gd}-\mathrm{Co} / \mathrm{Co}$, являющейся искусственным ферримагнетиком и выполняющей роль одного из рабочих слоев клапана. Обменносвязанная двухслойная пленка $\mathrm{Gd}-\mathrm{Co} / \mathrm{Co}$ ведет себя как единое целое под воздействием относительно слабых магнитных полей. Структура работает на основе того, что величины коэрцитивной силы двухслойной пленки Gd-Co/Co и свободного слоя Со различаются, делая возможным последовательное послойное перемагничивание многослойной пленки $\mathrm{Gd}-\mathrm{Co} / \mathrm{Co} / \mathrm{Cu} / \mathrm{Co}$. Магниторезистивная петля гистерезиса, измеренная на многослойной структуре $\mathrm{Gd}-\mathrm{Co} / \mathrm{Co} / \mathrm{Cu} / \mathrm{Co}$ в относительно малых полях, имеет вид, характерный для спиновых клапанов, электрическое сопротивление которых зависит от взаимной ориентации намагниченности слоев Со, разделенных прослойкой меди (вставка на рис. 1).

Известно также, что в двухслойной системе $\mathrm{Gd}-\mathrm{Co} / \mathrm{Co}$ возможно возникновение неколлинеарной магнитной структуры под воздействием относительно сильного магнитного поля, эволюция которой сопровождается, в том числе, изменением электрического сопротивления пленки $[4,5]$. Таким образом, можно ожидать нетривиального изменения электрического сопротивления спинового клапана $\mathrm{GdCo} / \mathrm{Co} / \mathrm{Cu} / \mathrm{Co}$ в широком диапазоне магнитных полей, как это наблюдалось, в частности, на спиновом клапане на основе синтетического антиферромагнетика [6].

\section{2. Методика исследований}

Многослойные пленки $\mathrm{Gd}-\mathrm{Co}(35 \mathrm{~nm}) / \mathrm{Co}\left(t_{\mathrm{Co}}\right) / \mathrm{Cu}\left(t_{\mathrm{Cu}}\right) /$ $\mathrm{Co}(7 \mathrm{~nm})$ были осаждены на стеклянные подложки методом магнетронного распыления соответствующих мишеней. Для формирования ферримагнитного слоя Gd-Co использовалась мозаичная мишень, представляющая собой диск Со с равномерно распределенными на нем таблетками Gd. Химический состав слоев Gd-Co был определен на специально полученных однослойных пленках с помощью энергодисперсионной рентгеновской спектроскопии и составил $\mathrm{Gd}_{23} \mathrm{Co}_{77}$. Величины $t_{\text {Со }}$ и $t_{\text {Сu }}$ варьировались в интервале от 1 до $7 \mathrm{~nm}$. В процессе осаждения пленок в плоскости подложек прикладывалось постоянное магнитное поле напряженностью 250 Ое для создания в пленках наведенной одноосной магнитной анизотропии. Рентгеноструктурные исследования показали, что слои Со и Сu находились в нано-кристаллическом, а слой Gd-Co в аморфном состоянии. Температурные и полевые зависимости магнитного момента образцов измерялись с помощью СКВИДмагнитометра MPMS XL7 EC. Магниторезистивные петли гистерезиса были получены с использованием четы- 


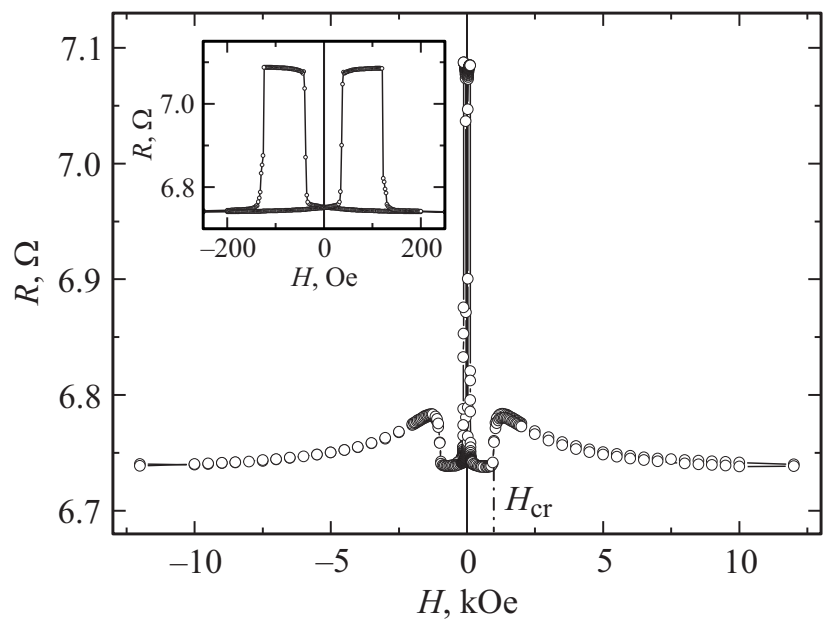

Рис. 1. Магниторезистивная петля гистерезиса, измеренная на спиновом клапане $\mathrm{GdCo}(35 \mathrm{~nm}) / \mathrm{Co}(7 \mathrm{~nm}) / \mathrm{Cu}(5 \mathrm{~nm}) / \mathrm{Co}(7 \mathrm{~nm})$ при $T=225 \mathrm{~K}$. На вставке показана часть петли в области малых полей.

рехзондового метода на установке PPMS DynaCool 9T, внешнее магнитное поле прикладывалось вдоль оси легкого намагничивания образца и параллельно току. Величина эффекта гигантского магнитосопротивления $\left(\right.$ ГМС) определялась как $\left[\left(R_{\max }-R_{\min }\right) / R_{\max }\right] \times 100 \%$, где $R_{\max }$ и $R_{\min }$ - максимальное и минимальное значения электросопротивления, полученные в результате анализа магниторезистивных петель гистерезиса.

\section{3. Полученные результаты}

На рис. 2, $a$ в качестве примера представлена магнитометрическая петля гистерезиса, измеренная на образце $\operatorname{GdCo}(35 \mathrm{~nm}) / \mathrm{Co}(7 \mathrm{~nm}) / \mathrm{Cu}(5 \mathrm{~nm}) / \mathrm{Co}(7 \mathrm{~nm})$ при температуре $T=225 \mathrm{~K}$, а на рис. $2, b$ показана в увеличенном масштабе центральная часть этой петли. Видно, что при амплитуде поля измерения $H$, не превышающей $0.9 \mathrm{kOe}$, петля представляет собой суперпозицию двух петель гистерезиса, соответствующих независимому перемагничиванию свободного слоя Со (слой Со, отделенный прослойкой $\mathrm{Cu}$ ) и обменно-связанной двухслойной пленки $\mathrm{Gd}-\mathrm{Co} / \mathrm{Co}$.

Ферримагнитный характер пленки $\mathrm{Gd}-\mathrm{Co} / \mathrm{Co}$ подтверждается специфическим видом температурной зависимости магнитного момента $M(T)$, измеренной на образце $\operatorname{GdCo}(35 \mathrm{~nm}) / \mathrm{Co}(7 \mathrm{~nm}) / \mathrm{Cu}(5 \mathrm{~nm}) / \mathrm{Co}(7 \mathrm{~nm})$ при $H=0.5 \mathrm{kOe} \quad$ (рис. 3,a). При $T=180 \mathrm{~K}$ в пленке $\mathrm{Gd}-\mathrm{Co} / \mathrm{Co}$ реализуется состояние магнитной компенсации, т.е. магнитный момент подсистемы Gd становится равным по модулю и противоположно направленным магнитному моменту подсистемы Сo.

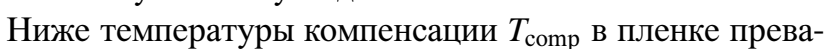
лирует магнитный момент подсистемы $\mathrm{Gd}$, а при более высоких температурах преобладает магнитный момент кобальтовой подсистемы. Во внешнем магнитном поле вдоль направления поля выстраивается преобладающий магнитный момент. Отличный от нуля сигнал от образца при $T_{\text {comp }}=180 \mathrm{~K}$ обусловлен магнитным моментом свободного слоя Со. Определенная путем деления данного сигнала на объем слоя Со намагниченность составила $1100 \mathrm{G}$, что меньше намагниченности объемного кобальта $(1420 \mathrm{G})$. Полученное заниженное значение намагниченности Со может быть обусловлено как размерным фактором [7], так и эффективным уменьшением объема слоя Со за счет его частичного поверхностного окисления

Анализ петель гистерезиса, измеренных при разных температурах, позволил определить температурную зависимость коэрцитивной силы $H_{c}$ свободного слоя Со и двухслойной пленки $\mathrm{Gd}-\mathrm{Co} / \mathrm{Co}$ (рис. $3, b$ ). Резкий рост $H_{c}$ двухслойной пленки $\mathrm{Gd}-\mathrm{Co} / \mathrm{Co}$ вблизи $T_{\text {comp }}$ является еще одним подтверждением ферримагнетизма системы $\mathrm{Gd}-\mathrm{Co} / \mathrm{Co}$.

Увеличение амплитуды поля измерения приводит к появлению на магнитометрических петлях гистерези-
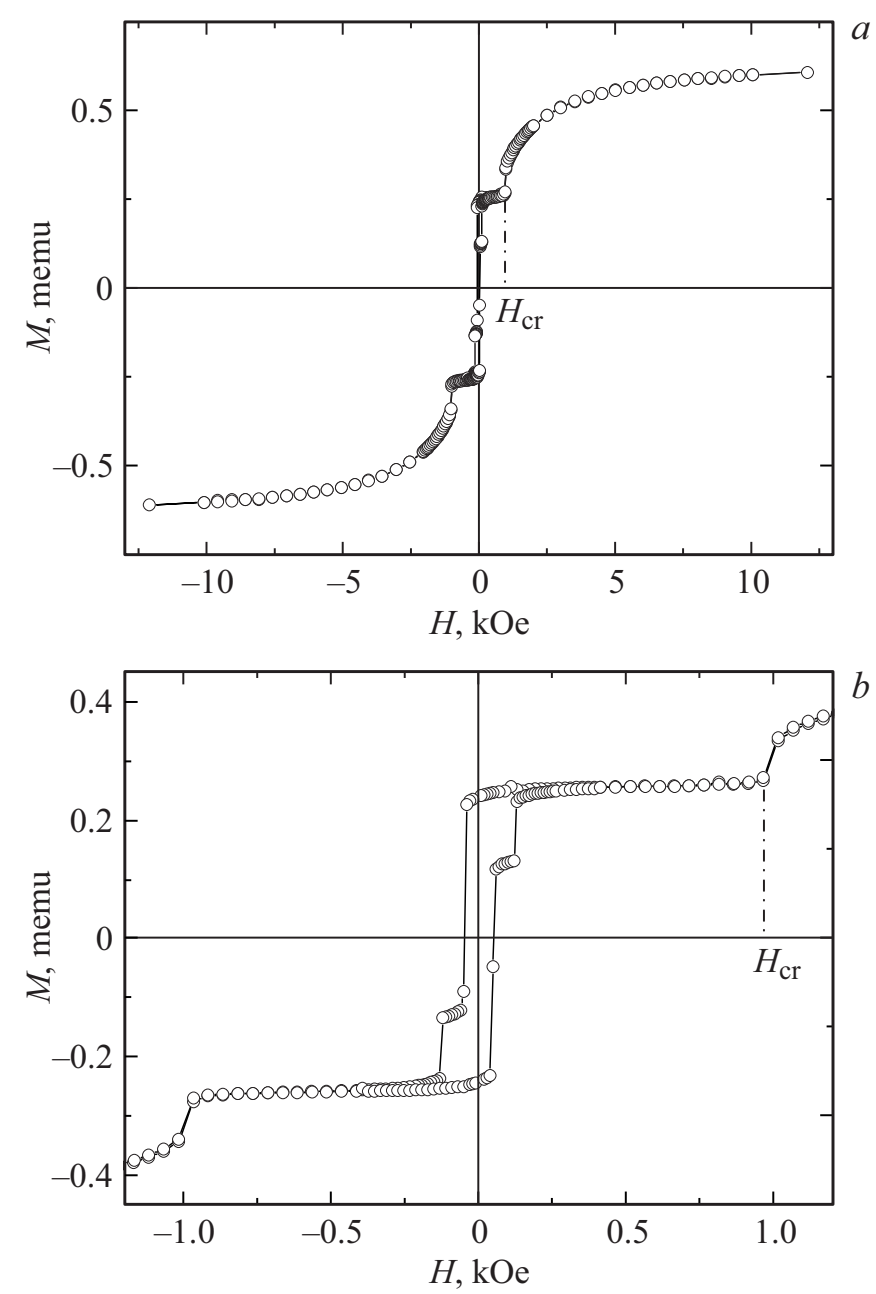

Рис. 2. Магнитометрическая петля гистерезиса, измеренная на спиновом клапане $\operatorname{GdCo}(35 \mathrm{~nm}) / \mathrm{Co}(7 \mathrm{~nm}) / \mathrm{Cu}(5 \mathrm{~nm}) /$ $\mathrm{Co}(7 \mathrm{~nm})$ при $T=225 \mathrm{~K}(a)$. центральная часть этой петли в области малых полей $(b)$. 

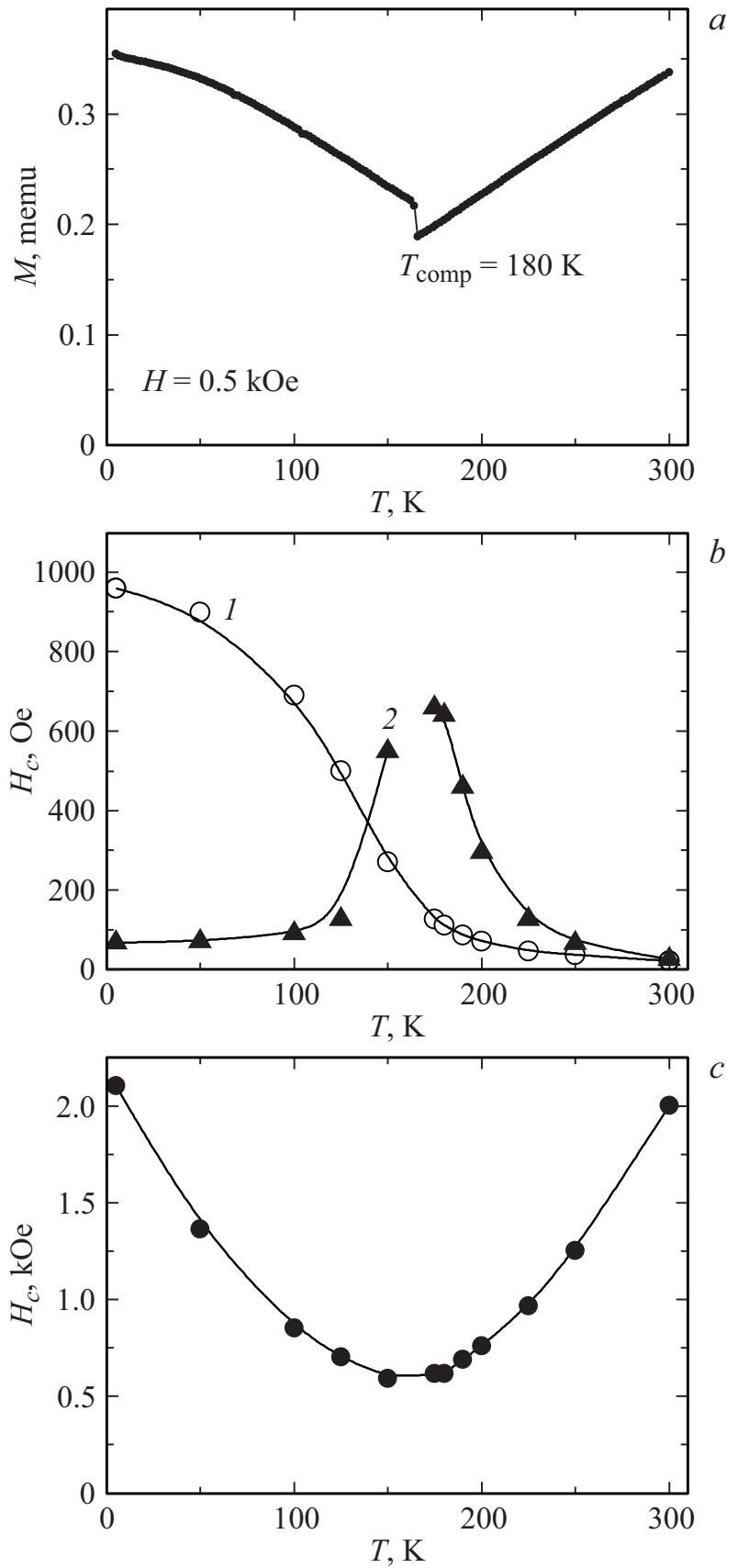

Рис. 3. Температурные зависимости магнитного момента $(a)$, коэрцитивной силы свободного слоя Со (кривая 1 ) и двухслойной пленки $\mathrm{Gd}-\mathrm{Co} / \mathrm{Co}$ (кривая 2) (b) и критического поля $(c)$ для образца $\mathrm{GdCo}(35 \mathrm{~nm}) / \mathrm{Co}(7 \mathrm{~nm}) / \mathrm{Cu}(5 \mathrm{~nm}) / \mathrm{Co}(7 \mathrm{~nm})$.

са характерных изломов, соответствующих возникновению неколлинеарной магнитной структуры в пленке Gd-Co/Co при $H=H_{\text {cr }}$ (рис. 2). Величина $H_{\text {cr }}$ уменьшается при приближении к $T_{\text {comp }}$ (рис. $\left.3, c\right)$ подобно тому, как это происходит в объемных ферримагнетиках [8].

Последующий рост поля вызывает эволюцию магнитной структуры, в результате которой магнитные моменты двух слоев Со и слоя Gd-Co оказываются выстроенными вдоль направления внешнего поля.
Описанный выше процесс намагничивания спинового клапана $\mathrm{GdCo} / \mathrm{Co} / \mathrm{Cu} / \mathrm{Co}$ находит свое отражение в особенностях магниторезистивных петель гистерезиса. На рис. 1 в качестве примера представлена такая петля, измеренная на образце $\operatorname{GdCo}(35 \mathrm{~nm}) / \mathrm{Co}(7 \mathrm{~nm}) /$ $\mathrm{Cu}(5 \mathrm{~nm}) / \mathrm{Co}(7 \mathrm{~nm})$ при температуре $T=225 \mathrm{~K}$, а на вставке показана в увеличенном масштабе центральная часть этой петли. Независимое перемагничивание свободного слоя Со и обменно-связанной двухслойной пленки Gd-Co/Co в области малых полей приводит к изменению взаимной ориентации намагниченностей слоев Со, разделенных прослойкой меди, что вызывает изменение электрического сопротивления многослойной структуры вследствие реализации эффекта гигантского магнитосопротивления. Возникновение неколлинеарной магнитной структуры в двухслойной пленке $\mathrm{Gd}-\mathrm{Co} / \mathrm{Co}$ при $H=H_{\text {cr }}$ сопровождается отклонением магнитного момента слоя Со от направления поля, что вызывает изменение сопротивления пленочной структуры. Строго говоря, изменение сопротивления может быть связано как с анизотропным магниторезистивным эффектом (AMP) в слое Со, так и с эффектом ГМС вследствие нарушения параллельности магнитных моментов слоев $\mathrm{Co}$, разделенных прослойкой меди. В данной геометрии реализация АМР должна приводить к уменьшению электросопротивления [9], а на эксперименте наблюдается его увеличение, поэтому основной вклад в изменение сопротивления обусловлен эффектом ГМС. Постепенное выстраивание магнитных моментов всех слоев вдоль направления поля при его увеличении ожидаемо сопровождается уменышением сопротивления спинового клапана.

При переходе через температуру компенсации пленки $\mathrm{Gd}-\mathrm{Co} / \mathrm{Co}$ изменяется знак наблюдаемого на спиновом клапане $\mathrm{GdCo} / \mathrm{Co} / \mathrm{Cu} / \mathrm{Co}$ эффекта ГМС [1]. Кроме того, вблизи $T_{\text {comp }}$ заметно меняется форма магниторезистивных петель (рис. 4). Это связано с тем, что в окрестностях $T_{\text {comp }}$ величины $H_{c}$ пленки $\mathrm{Gd}-\mathrm{Co} / \mathrm{Co}$ и $H_{\text {сr }}$ становятся сравнимы (рис. $\left.3, b, c\right)$, потому неколлинеарная магнитная структура возникает еще до того, как закончится перемагничивание пленки Gd-Co/Co как единого целого.

При $T<140$ К изменяется очередность перемагничивания свободного слоя Со и пленки Gd-Co/Co, так как коэрцитивная сила последней становится меньше, чем у свободного слоя Со (рис. 3, $b$ ). Это практически не сказывается на величине эффекта ГМС, наблюдаемого в области малых полей и составляющего примерно $3.5 \%$ (рис. 1 и 5).

Удаление от $T_{\text {comp }}$ в область низких или высоких температур заметно сказывается на величине ГМС, обусловленного возникновением неколлинеарной магнитной структуры (рис. 1 и 5). Это связано с тем, что при высоких температурах в двухслойной пленке $\mathrm{Gd}-\mathrm{Co} / \mathrm{Co}$ преобладает магнитный момент кобальтовой подсистемы, поэтому при возникновении неколлинеарной фазы отклонение магнитного момента Со от направления 


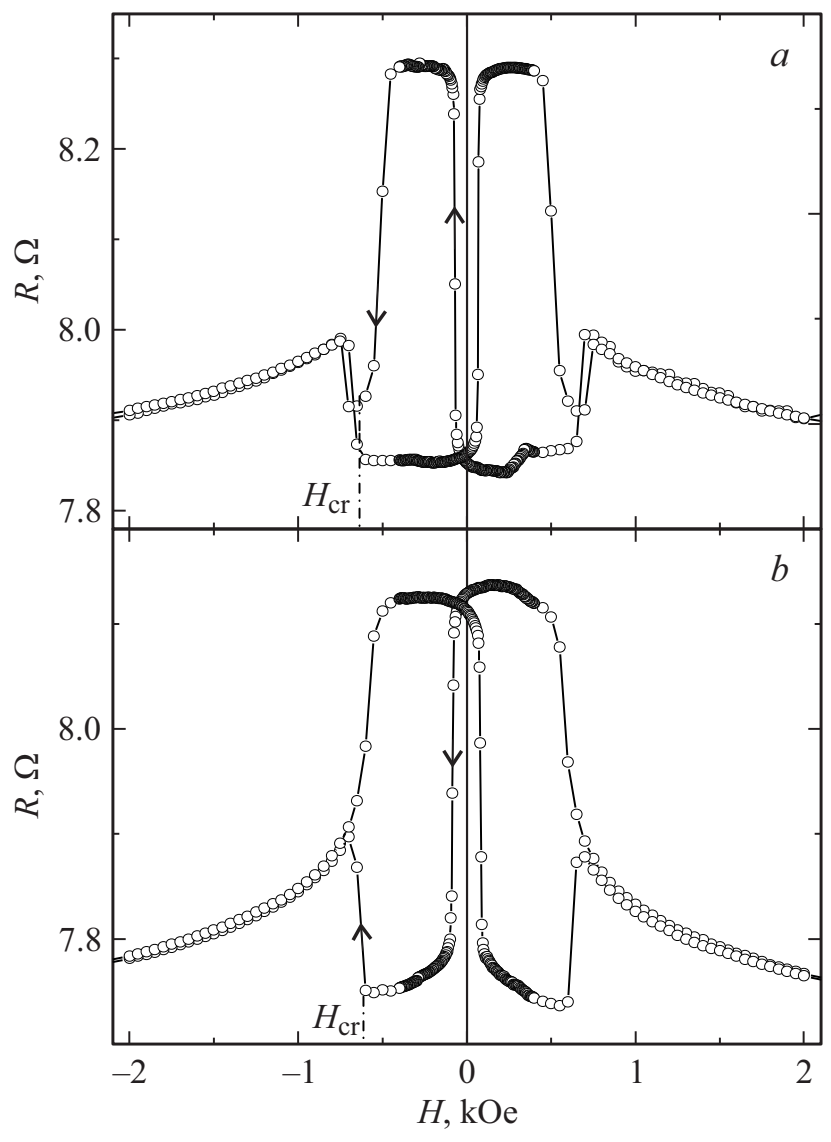

Рис. 4. Магниторезистивные петли гистерезиса, измеренные на спиновом клапане $\operatorname{GdCo}(35 \mathrm{~nm}) / \mathrm{Co}(7 \mathrm{~nm}) / \mathrm{Cu}(5 \mathrm{~nm}) /$ $\mathrm{Co}(7 \mathrm{~nm})$ при $T=190 \mathrm{~K}(a)$ и $T=170 \mathrm{~K}(b)$.

внешнего магнитного поля не превышает $90^{\circ}$, и этот угол отклонения уменьшается с увеличением температуры. И наоборот, при низких температурах в двухслойной пленке Gd-Co/Co преобладает магнитный момент подсистемы $\mathrm{Gd}$, поэтому до возникновения неколлинеарной фазы магнитный момент слоя Со направлен против внешнего магнитного поля, а при ее эволюции изменяет свое направление на $180^{\circ}$, тем самым изменяя ориентацию относительно магнитного момента свободного слоя Со от антипараллельной до параллельной. Таким образом, величина ГМС оказывается одинаковой как при послойном перемагничивании спинового клапана $\mathrm{GdCo} / \mathrm{Co} / \mathrm{Cu} / \mathrm{Co}$ в области относительно малых полей, так и при эволюции неколлинеарной фазы в больших полях (рис. 5).

Значительное увеличение $H_{c}$ свободного слоя Со при $T<170 \mathrm{~K}$ может быть обусловлено не только температурной зависимостью магнитокристаллической анизотропии кобальта, но и влиянием поверхностного антиферромагнитного оксида кобальта. Известно, что в системе $\mathrm{Co} / \mathrm{CoO}$ при температурах ниже температуры Нееля $\left(T_{\mathrm{N}}\right)$ оксида кобальта возникает однонаправленная анизотропия, проявляющаяся в смещении петли гистерезиса Со и увеличении его коэрцитивной силы [10].
Для массивного образца $\mathrm{CoO} T_{\mathrm{N}}=289 \mathrm{~K}$ [11]. Однако, хорошо известно, что вследствие влияния размерного фактора $T_{\mathrm{N}}$ резко уменьшается, если толщина пленки составляет единицы нанометров [12]. Если предположить, что эффективное уменьшение намагниченности свободного слоя Со связано с его поверхностным окислением, то толщина $\mathrm{CoO}$ будет составлять $\sim 1.5 \mathrm{~nm}$. Вполне логично предположить, что для такой толщины $\mathrm{CoO} T_{\mathrm{N}}$ может составлять примерно $170 \mathrm{~K}$. Для реализации смещения петли гистерезиса требуется выполнение условия $K_{\mathrm{CoO}} \times t_{\mathrm{CoO}} \geq J_{\text {int }}$, где $K_{\mathrm{CoO}}-$ константа анизотропии $\mathrm{CoO}, t_{\mathrm{CoO}}$ - толщина $\mathrm{CoO}, J_{\text {int }}$ - константа межслойной связи на границе раздела $\mathrm{Co} / \mathrm{CoO}$ [13]. В нашем случае данное условие, по-видимому, не выполняется, так как отсутствует смещение петли магнитного гистерезиса свободного слоя Со, и лишь увеличивается его коэрцитивная сила.

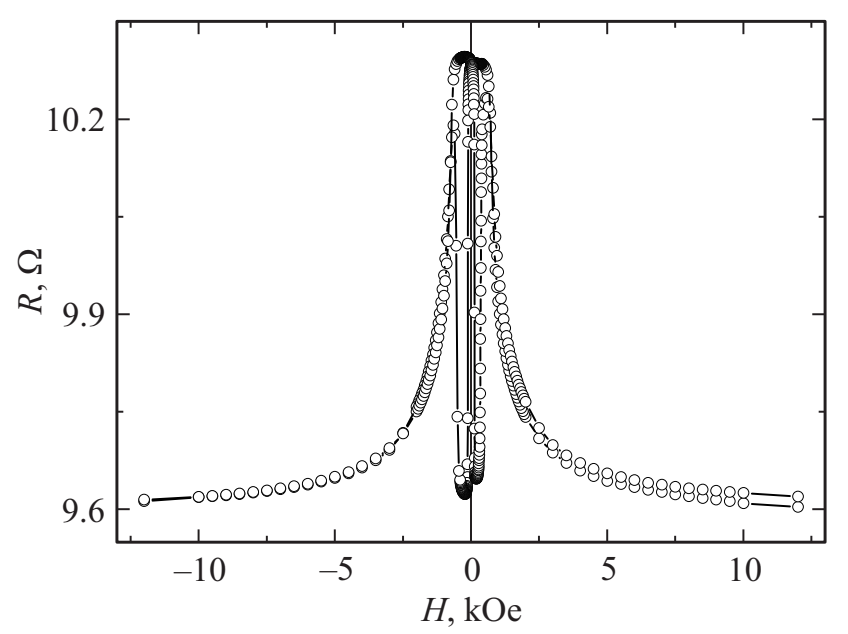

Рис. 5. Магниторезистивная петля гистерезиса, измеренная на спиновом клапане $\mathrm{GdCo}(35 \mathrm{~nm}) / \mathrm{Co}(7 \mathrm{~nm}) / \mathrm{Cu}(5 \mathrm{~nm}) / \mathrm{Co}(7 \mathrm{~nm})$ при $T=125 \mathrm{~K}$.

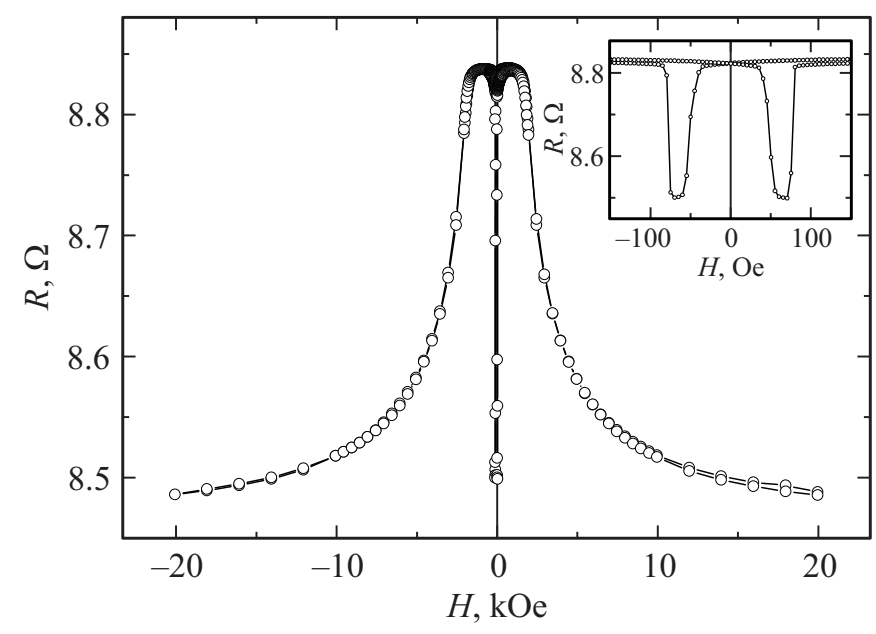

Рис. 6. Магниторезистивная петля гистерезиса, измеренная на спиновом клапане $\mathrm{GdCo}(35 \mathrm{~nm}) / \mathrm{Co}(3 \mathrm{~nm}) / \mathrm{Cu}(5 \mathrm{~nm}) / \mathrm{Co}(7 \mathrm{~nm})$ при $T=190 \mathrm{~K}$. 
Изменением химического состава слоя Gd-Co, а также толщин слоев в двухслойной пленке $\mathrm{Gd}-\mathrm{Co} / \mathrm{Co}$ можно варьировать величину $T_{\text {comp, }}$, следовательно, и форму магниторезистивной петли гистерезиса при заданных температурах. В качестве примера на рис. 6 показана магниторезистивная петля гистерезиса, измеренная на спиновом клапане $\operatorname{GdCo}(35 \mathrm{~nm}) / \mathrm{Co}(3 \mathrm{~nm}) /$ $\mathrm{Cu}(5 \mathrm{~nm}) / \mathrm{Co}(7 \mathrm{~nm})$ при $T=190 \mathrm{~K}$. Она заметно отличается от петли, измеренной на спиновом клапане $\mathrm{GdCo}(35 \mathrm{~nm}) / \mathrm{Co}(7 \mathrm{~nm}) / \mathrm{Cu}(5 \mathrm{~nm}) / \mathrm{Co}(7 \mathrm{~nm})$ при той же температуре (рис. 4, $a$ ), но подобна петле, измеренной на нем при $T=125 \mathrm{~K}$. Таким образом, варьируя параметры слоев в системе Gd-Co/Co можно добиться максимального возможного для спинового клапана $\mathrm{GdCo} / \mathrm{Co} / \mathrm{Cu} / \mathrm{Co}$ изменения сопротивления при эволюции неколлинеарной магнитной структуры под воздействием внешнего магнитного поля.

Полученный набор характеристик показывает, что спиновый клапан на основе искусственного ферримагнетика обладает не только способностью работать в режиме триггера, поле срабатывания которого зависит от температуры, но и монотонно изменять свое сопротивление под действием внешнего магнитного поля, что может использоваться, например, для создания детекторов прецизионного определения положения объекта.

\section{4. Заключение}

Пленочные структуры типа $\mathrm{Gd}-\mathrm{Co} / \mathrm{Co} / \mathrm{Cu} / \mathrm{Co}$ были разрабтаны, получены и исследованы с целью создания термочувствительных спиновоых клапанов, адаптированных к работе в широком диапазоне полей и температур. На основе исследования закономерностей перестройки магнитной структуры спиновых клапанов $\mathrm{GdCo} / \mathrm{Co} / \mathrm{Cu} / \mathrm{Co}$ во внешнем магнитном поле установлено, что коллинеарная магнитная структура приобретает неколлинеарный характер в результате возникновения угловой фазы в двухслойной пленке $\mathrm{GdCo} / \mathrm{Co}$. Форма магниторезистивной петли, измеренной на спиновом клапане, зависит от температуры и параметров слоев пленки $\mathrm{GdCo} / \mathrm{Co}$. Представленные результаты могут служить основанием для расширения функциональных возможностей спиновых клапанов.

\section{Финансирование}

Работа выполнена при финансовой поддержке Российского фонда фундаментальных исследований (грант № 17-02-00236-a).

\section{Конфликт интересов}

Авторы заявляют, что у них нет конфликта интересов.

\section{Список литературы}

[1] A.V. Svalov, G.V. Kurlyandskaya, V.O. Vas'kovskiy. Appl. Phys. Lett. 108, 063504 (2016).

[2] M. Milyaev, L. Naumova, T. Chernyshova, V. Proglyado, I. Kamensky, T. Krinitsina, M. Ryabukhina, V. Ustinov. J. Appl. Phys. 121, 123902 (2017).

[3] Л.И. Наумова, М.А. Миляев, Т.П. Криницина, В.В. Макаров, М.В. Рябухина, Т.А. Чернышова, И.К. Максимова, В.В. Проглядо, В.В. Устинов. ФММ 119, 817 (2018).

[4] В.О. Васьковский, А.В. Свалов, К.Г. Балымов, Г.В. Курляндская, А.Н. Сорокин. ФТТ 50, 1424 (2008).

[5] J.P. Andrés, J.A. González, T.P.A. Hase, B.K. Tanner, J.M. Riveiro. Phys. Rev. B 77, 144407 (2008).

[6] Л.И. Наумова, М.А. Миляев, Т.А. Чернышова, В.В. Проглядо, Н.С. Банникова, Т.П. Криницина, В.В. Устинов. Наноинженерия 12, 15 (2015).

[7] A.V. Svalov, V.O. Vas'kovskiy, G.V. Kurlyandskaya. Phys. Met. Metallogr. 118, 1263 (2017).

[8] К.П. Белов, А.К. Звездин, А.М. Кадомцева, Р.З. Левитин. Ориентационные переходы в редкоземельных магнетиках. Наука, М. (1979). 317 c.

[9] B.D. Cullity, C.D. Graham. Introduction to Magnetic Materials. 2nd ed. Jon Wiley and Sons, New Jersey (2009). 544 p.

[10] W.H. Meiklejohn, C.P. Bean. Phys. Rev. 102, 1413 (1956).

[11] M.D. Rechtin, S.C. Moss, B.L. Averbach. Phys. Rev. Lett. 24, 1485 (1970).

[12] X.Y. Lang, W.T. Zheng, Q. Jiang. Phys. Rev. B 73, 224444 (2006).

[13] W.H. Meiklejohn. J. Appl. Phys. Suppl. 33, 1328 (1962).

Редактор Д.В. Жуманов 